\title{
4 \\ Political Institutions and Financial Development
}

\subsection{Introduction}

Over the last few decades, there has been a substantial increase in financial development in many developing countries. The average ratio of private credit to GDP increased from $23 \%$ in 1980 to $32 \%$ in 2000 , while the average ratio of liquid liabilities to GDP rose from $32 \%$ in 1980 to $42 \%$ in 2000 in the developing world. On the political front, between 1980 and 200062 developing countries undertook significant institutional reforms towards democracy. ${ }^{58}$ Do the above economic and political events in the developing world interact in important ways?

Much work has been done to explore the relationship between institutional improvement, especially political liberalization, and economic growth. The existing research in this field does not unanimously establish the consequences of political reform for economic development. Instead, it is made up of one line of research supporting positive consequences, another line stressing negative consequences and some maintaining ambiguous views. How does democratic process to improve institutional quality influence financial development, especially in countries with low GDP per capita, high ethnic and religious divisions or specific legal origins?

The importance of institutional improvement for financial development has been implicitly indicated by Clague et al. (1996) and Olson (1993), who argue that, in comparison to autocracies, democracies better facilitate property rights protection and contract enforcement, encouraging investment directly. In recent research on the political economy of financial development, Pagano and Volpin (2001), Rajan and Zingales (2003) and Beck et al. (2003) highlight the role of political intervention and institutions in financial development. In examining what forces lead 
governments to undertake reforms to enhance financial development, Chapter 5 finds that the extent of democracy is one of the significant forces. However, there has been little research which directly studies the impact of the democratic process for institutional improvement on financial development.

This analysis mainly carries out a dynamic panel data study, focusing on 90 developed and developing countries. It examines the impact on financial development of the democratic process in a broader sense, in terms of institutional improvement rather than political transformation. ${ }^{59}$ The bias-corrected Least Square Dummy Variable (LSDV) estimator proposed by Kiviet (1995) and recently developed by Bruno (2005) is the central method of this study and is compared with the system GMM estimator proposed by Arellano and Bover (1995) and Blundell and Bond (1998).

Before proceeding to the econometric analysis, this research provides some preliminary evidence with a before-and-after event comparison to study probably the most important institutional change, namely political transformation from an autocratic regime to a democratic one. It focuses on 33 countries which underwent a democratic transformation during 1960-2000 subject to data availability for financial development. This exercise examines the responses of the level and volatility of financial development after a regime transition.

This chapter shows that improved institutional quality is associated with increases in financial development at least in the short run, especially for lower-income, ethnically divided and French legal origin countries. The before-and-after event study also indicates that, in general, democratic transitions are typically preceded by low financial development, but followed by a short-run boost in, and greater volatility of, financial development. The findings of this research underline the influence of institutional reform over the supply side of finance and shed light on the strong and robust relationship between institutional quality and economic performance.

The remainder of the chapter proceeds as follows. Section 4.2 presents a brief review of the literature on institutions, democratization and finance. Section 4.3 describes the sample and measures that are used in this study. The empirical results are presented in Section 4.5, following a description of dynamic panel data methods in Section 4.4. Section 4.6 concludes.

\subsection{Institutions, democratization and finance}

This section briefly outlines the theoretical background and motivation of this research. It discusses the role of institutions in financial 
development and the possible links between the democratic process and finance.

Research on the effect of institutional reform on general economic performance is associated with substantial controversies. Some argue that the democratic process enhances fundamental civil liberties, stable politics and an open society; promotes property rights protection and contract enforcement; discourages corruption and lawlessness and fosters economic growth (Olson, 1993; Clague et al., 1996; Minier, 1998 and Persson, 2005). On the contrary, under pressures from different interest groups, democratic structures may suffer from inefficiency in decision-making and difficulty in implementing viable policies for rapid growth. "Premature" democracy in developing countries possibly lowers the economic growth rate, and even results in economic disorder, political instability and ethnic conflict (Persson and Tabellini, 1992 and Blanchard and Shleifer, 2000). Tavares and Wacziarg (2001) show that "the overall effect of democracy on economic growth is moderately negative" - an increase in human capital accumulation is offset by a decrease in physical capital accumulation in the process of democratization.

Research on the role of institutions in financial development has been substantial, especially research on the effects of the legal and regulatory environment on the functioning of financial markets. A legal and regulatory system involving protection of property rights, contract enforcement and good accounting practices has been identified as essential for financial development. Most prominently, La Porta et al. (1997, 1998) have argued that the origins of the legal code substantially influence the treatment of creditors and shareholders, and the efficiency of contract enforcement. ${ }^{60}$ Among others, Mayer and Sussman (2001) emphasize that regulations concerning information disclosure, accounting standards, permissible banking practices, and deposit insurance do appear to have material effects on financial development.

Another significant work in this context is Beck et al. (2003), which extends the settler mortality hypothesis of Acemoglu et al. (2001) to financial development. They argue that colonizers, often named as extractive colonizers, associated with an inhospitable environment aim to establish institutions that privilege the small elite group and potentially ignore private property rights, while colonizers, often called settler colonizers, in more favourable environments are more likely to create institutions that support private property and balance the power of the state. Accordingly, institutions in the extractive environment tend to block financial development, while those in settler colonies are more conducive to financial development.

The recently developed "new political economy" approach regards "regulation and its enforcement as a result of the balance of power 
between social and economic constituencies" (Pagano and Volpin, 2001). It centres on self-interested policy-makers who can intervene in financial markets either through overall regulation or individual cases for purposes such as career concerns and the promotion of group interests. Rajan and Zingales (2003) emphasize the role which the interest groups, especially the incumbent industrial firms and the domestic financial sector, can play in the process of financial development. ${ }^{61}$

Arguably, countries controlled by elite groups are more inclined to protect the interests of the elite from the bulk of society, restrict participation in the political system, and so on. The more power held by the elite groups and the more autocratic the system, the more obstacles there are for financial development. This tends to suggest that institutional reform intending to limit the influence of elite group over policy-making, widen suffrage in the political system, respect basic political rights and civil liberties, remove institutional obstacles and enhance institutional efficiency is beneficial to financial development. Girma and Shortland (2008) study the impact of democracy chrematistics and regime change on financial development, showing that both democracy and regime change promote financial development. ${ }^{62}$ Apart from Girma and Shortland (2008), research directly exploring the impact of democratic process for institutional improvement on financial development has been lacking.

This research might contribute to our understanding of the structural determinants of financial development. Looking at this issue is also significant for examining whether institutional innovation contributes to an improved investment climate. This is because commonly used financial development indicators such as the ratio of liquid liabilities to GDP and the ratio of credit issued to the private sector to GDP are generally forward-looking. Better financial development is then an early indication of a better investment environment.

\subsection{The measures and data}

\subsubsection{The sample}

This research studies the impact of institutional improvement on financial development, controlling for GDP, trade openness, aggregate investment and the black market premium. The measures and data for financial development and institutional improvement are explained in more detail below. Information on the classifications of income levels, region dummies, ethnic fractionalization and legal origins is obtained from the 
World Bank Global Development Network Database (GDN) (2002). The data for GDP, trade openness and aggregate investment are from the Penn World Table 6.2. Data for the black market premium are from the GDN (2002).

This study focuses on a panel of 90 non-transition economies over the period 1960-99 with five observations per country. Averaging data over non-overlapping, eight-year periods enables us to abstract from business cycle influences and to examine both short-run and long-run effects. The countries included for this analysis are those undertaking some political reforms to improve institutional quality, but not necessarily experiencing a democratic transition over 1960-99. The sample excludes the East European countries, ${ }^{63}$ which became democracies and independent only following the end of the Cold War. The selection of countries is based on the Polity index, "polity2" of the PolityIV Database explained below. We naturally use data up to the end of the twentieth century, which is partly because of data availability for some important variables, like the black market premium, ${ }^{64}$ and partly because annual data for 40 years are sufficient for a dynamic panel data study.

\subsubsection{The measure and data for financial development}

The aggregate measure of financial development in this context is denoted by $F D$. Since there is no single aggregate index in the literature, we use principal components analysis to produce a new aggregate index. Ideally, the principal component analysis should be based on indicators from the banking sector, stock market and bond market so as to capture different aspects of financial development. However, data on stock market and bond market development are rarely available for before 1975 or even later, so the analysis focuses on financial intermediary development.

The measure is based on three widely used indicators of financial intermediary development as follows: 65

1. Liquid Liabilities $(L L Y)$, calculated as the liquid liabilities of banks and non-bank financial intermediaries (currency plus demand and interest-bearing liabilities) over GDP. It measures the size, relative to the economy, of financial intermediaries including three types of financial institutions: the central bank, deposit money banks and other financial institutions.

2. Private Credit (PRIVO), defined as the credit issued to the private sector by banks and other financial intermediaries divided by GDP, excluding the credit issued to government, government agencies and public enterprises, as well as the credit issued by the monetary authority 
and development banks. This captures general financial intermediary activities provided to the private sector.

3. Commercial-Central Bank (BTOT), the ratio of commercial bank assets over the sum of commercial bank and central bank assets. It proxies the advantages of financial intermediaries in channelling savings to investment, monitoring firms, exerting corporate governance and undertaking risk management relative to the central bank.

Since these indicators are used to measure the size of the banking system, ${ }^{66}$ FD mainly captures the size of bank-based intermediation. FD is the first principal component of these three indicators above, and accounts for $72 \%$ of their variation. The weights resulting from principal component analysis over the period 1990-99 are 0.59 for Liquid Liabilities, 0.63 for Private Credit and 0.50 for Commercial-Central Bank.

The data on these indicators are obtained from the World Bank's Financial Structure and Economic Development Database (2008).

\subsubsection{The measure and data for institutional improvement}

The research focuses on political institutions and studies their impact on financial development. The institutional improvement index is the Polity indicator "polity2" in the PolityIV Database (Marshall and Jaggers, 2009), denoted by POLITY2. It proxies the degree of democracy and seeks to measure institutional quality based on the freedom of suffrage, operational constraints and balances on executives and respect for other basic political rights and civil liberties. It is called the "combined polity score", 67 defined as the democracy score minus the autocracy score. ${ }^{68}$

To pick up any effect of institutional improvement on financial development, this exercise tries to incorporate all democratic reform episodes in the sense that any increase of the annual "polity2" score for a country will be considered even if it remains an autocratic regime or a democratic regime over the whole period.

To select democratic transition countries for the before-and-after event study, we also take into account the freedom index from Freedom House Country Survey (2008).

\subsection{Methodology}

To assess the relationship between institutional improvement and financial development, the following model is estimated: ${ }^{69}$

$$
\begin{aligned}
y_{i t} & =\alpha y_{i, t-1}+\beta x_{i, t-1}+z_{i, t-1}^{\prime} \delta+\eta_{i}+\phi_{t}+v_{i t} \\
i & =1,2, \ldots 90 \text { and } t=2 \ldots 5
\end{aligned}
$$


where $y_{i t}$ is the dependent variable $F D, x_{i t}$ is the explanatory variable POLITY2, $z_{i t}$ is a vector of controlling variables including the logarithm of the real GDP per capita $(L G D P)$, trade openness (OPENC), aggregate investment $(C I)$ and the black market premium $(B M P)$. OPENC is the logarithm of one plus the trade share, the sum of exports and imports over GDP (at current prices), divided by 100 . $C I$ is the ratio of investment to real GDP per capita (using domestic prices), divided by 100. BMP is the logarithm of one plus the black market premium divided by $100 . \delta$ is a parameter vector, e.g. $\left(\delta_{1}, \ldots \delta_{4}\right)^{\prime} \cdot \eta_{i}$ is an unobserved time-invariant country-specific effect and can be regarded as capturing the combined effect of all omitted variables. $\phi_{t}$ is the time effect. $v_{i t}$ is the transitory disturbance term.

We assume that the transient errors $v_{i t}$ are serially uncorrelated. In system GMM estimation all $x^{\prime} s$ and $z^{\prime} s$ are assumed to be potentially correlated with $\eta_{i}$ and predetermined with respective to time-varying errors. $^{70}$ To avoid the potential endogeneity of explanatory variables, lagged values of $x_{i, t}$ and $z_{i, t}$ are included in the regression equation, which allows feedback from the past shocks onto $x_{i, t-1}$ and $z_{i, t-1}$ while the current and future realizations of $y_{i t}$ do not affect them. The assumption is inspired by Rodrik and Wacziarg (2005), who argue that "democratisations tend to follow periods of low growth rather than precede them". In contrast to the GMM approach, the following biascorrected Least Squares Dummy Variable (LSDV) estimation assumes all $x^{\prime} s$ and $z^{\prime} s$ to be strictly exogenous, which rules out the possibility of feedbacks from the past, current and future shocks onto $x_{i, t-1}$ and $z_{i, t-1}$.

When the Ordinary Least Square (OLS) technique is used to estimate this model, the OLS estimate of $\alpha$ is inconsistent and likely to be biased upwards since the lagged values of $y_{i t}$ are positively correlated with the omitted fixed effects.

A number of methods have been developed to deal with the presence of fixed effects in the dynamic panel data model. By using a within group operator, the LSDV method eliminates any omitted variables bias created by the unobserved individual effect and estimates the new model below by OLS:

$$
\begin{aligned}
y_{i t}-\overline{y_{i}}= & \alpha\left(\mathbf{y}_{i, t-1}-y_{i,-1}^{-}\right)+\left(x_{i, t-1}-x_{i,-1}^{-}\right) \beta \\
& +\left(z_{i, t-1}-z_{i,-1}\right) \delta+\left(v_{i t}-\overline{v_{i}}\right) \\
i= & 1,2, \ldots 90 \text { and } t=2 \ldots 5
\end{aligned}
$$


where $\bar{y}_{i}, \bar{x}_{i}$ and $\bar{z}_{i}$ are the group means, that is, $\bar{y}_{i}=\sum_{t=2}^{5} y_{i t} / 5, \bar{x}_{i}=$ $\sum_{t=2}^{5} x_{i t} / 5$ and $\overline{z_{i}}=\sum_{t=2}^{5} z_{i t} / 5$. Since the lagged value of $y$ is correlated with the new error term, as shown by Nickell (1981), the LSDV estimate of $\alpha$ can be badly downwards biased for small $T$, even as $N$ goes to infinity.

Another way commonly used to wipe out the individual effects is to apply first-differencing to Equation (3.1). By estimating the following first-difference equation, the first-difference 2SLS estimator of Anderson and Hsiao (1980, 1981), first-differenced GMM estimator of Arellano and Bond (1991) and the system GMM estimator of Arellano and Bover (1995) and Blundell and Bond (1998) are proposed among others:

$$
\begin{aligned}
\Delta y_{i t} & =\alpha \Delta \mathbf{y}_{i, t-1}+\Delta x_{i, t-1} \beta+\Delta z_{i, t-1}^{\prime} \delta+\phi_{t}-\phi_{t-1}+\Delta v_{i t} \\
i & =1,2, \ldots 90 \text { and } t=3 \ldots 5
\end{aligned}
$$

Conventional wisdom suggests that the first-differenced GMM estimator is consistent and asymptotically more efficient than the firstdifferenced 2SLS estimator. However, it may suffer from finite sample bias by employing weak instruments, as argued by Blundell and Bond (1998), that is, that "when the autoregressive parameter $\alpha$ is close to unity or the variance of the individual effects $\left(\eta_{i}\right)$ increases relative to the variance of the transient disturbances $\left(v_{i t}\right)$ in the standard AR(1) model, the instruments available for the first-differenced equation are likely to be weak".

To handle the weak instrument problem, Arellano and Bover (1995) and Blundell and Bond (1998) impose a mean stationarity assumption on initial conditions, ${ }^{71}$ and combine the first-difference equations with suitably lagged levels as instruments and levels equations with suitably lagged first differences as instruments. More specifically, the system GMM estimator, one of the main focuses of this analysis, uses all lagged values of $\mathrm{y}, \mathrm{x}$ and $\mathrm{z}$ as instruments for $\Delta \mathrm{y}_{i, t-1}, \Delta \mathrm{x}_{i, t-1}$ and $\Delta \mathrm{z}_{i, t-1}$ in the first difference equation above, ${ }^{72}$ and the lagged first differences of the series $\left(y_{i t}, x_{i t}, z_{i t}\right)$ dated $t-1$ as instruments for the untransformed equations in levels. ${ }^{73}$ The system GMM estimator has been found to be more efficient than the first-differenced GMM estimator in the presence of persistent data and weak instruments for first differences.

The asymptotic properties of the system GMM estimator depend on having a large number of cross section units, however. One of the main problems in using this estimator is that it may have poor finite sample properties in terms of bias and imprecision. Starting from Kiviet (1995), 
a bias correction of LSDV has recently been developed for use in short dynamic panels. Kiviet (1995) derives an approach to approximating the small sample bias of the LSDV estimator and suggests that the bias approximation be evaluated at the estimates from some consistent estimates rather than the unobserved true parameter values, which makes bias correction operationally feasible. The Monte Carlo evidence from Kiviet (1995), Judson and Owen (1999) and Bun and Kiviet (2003) suggests that the bias-corrected LSDV estimator (LSDVC) is more efficient than LSDV, first-differenced 2SLS, first-differenced GMM and system GMM in terms of bias and root mean square error (RMSE) for small or moderately large samples. Bruno (2005) derives a bias approximation of various orders in dynamic unbalanced panels with a strictly exogenous selection rule. ${ }^{74}$

This analysis compares the OLS, LSDV, LSDVC and SYS-GMM, standing for the system GMM estimator, for the whole sample and three subsamples. The LSDVC estimator is regarded as the preferred estimator, especially for subsamples, even though the independent variables other than the lagged dependent variable are assumed to be strictly exogenous. The initial estimator for the LSDVC could be either first-differenced GMM or the SYS-GMM estimator. However, the SYS-GMM is selected since the Difference Sargan test of additional moments conditions could not reject the null, and the SYS-GMM may be a more reliable estimator than first-differenced GMM in this context.

\subsection{Evidence}

The econometric methods are applied to study the effect on financial development of a broader issue, that is institutional improvement, based on even a slight change of the Polity index, "polity2". Before proceeding to the econometric analysis, we look at some preliminary evidence on the effect of the establishment of representative government on financial development by applying a "before-and-after" approach to 33 countries which underwent transformation from autocratic regimes to complete or partial democracies at some point during 1960-2001.

\subsubsection{Preliminary evidence}

The sample selection for the "before-and-after" event study relies on both the "polity2" index and "freedom" index from the Freedom House Country Survey (2008). Countries with either their "polity2" index increasing from negative values to positive values or their "freedom" index jumping from "Not Free" to "Partly Free" or "Free" for at least ten years are 
considered for this analysis. In general, the "polity2" and "freedom" indices yield similar results on the timing of democratic transition for most cases. However, the "polity2" index excludes countries with small populations (less than half a million) and the "freedom" index is only available starting from $1972-73 .^{75}$ For completeness, the selection of democratic transition countries combines both indices when both are available and relies on either of them otherwise.

The "before-and-after" approach compares an individual country's financial development performance under autocratic and democratic regimes. ${ }^{76}$ To ease interpretation, the $F D$ measure has been rescaled ${ }^{77}$ in Table 4.1. The five- or ten-year average of $F D$ preceding democratic transition is compared with the mean of $F D$ during the first five or ten years under democracy for 33 countries.

The ten-year average of standardized FD for the sample countries increases by 0.093 on average after the initiation of a democratic transition and more than half of the sample countries exhibit an improvement in financial development. ${ }^{78}$ It is worth noting that the majority of countries which suffered from a dramatic drop in financial development after democratization are Latin American countries. In contrast, most African countries underwent a pick-up in financial development after their democratic transformations. The divergent performance in countries' financial development implies that, apart from democratization, the level of financial development in each country may be affected by numerous factors including macroeconomic risks and changes in the general investment climate. ${ }^{79}$ On average, these results tend to suggest that the establishment of representative government is often associated with an increase in financial development, but the effect is only sizeable for a subset of countries.

The upper chart of Figure 4.1 displays the cross-country median FD ten years before and after transition for the whole sample. The lower chart of Figure 4.1 plots the coefficients on the fixed-effect estimate of 20 time dummies before and after democratisation to reflect the dynamic effect of a sustained democratization. ${ }^{80}$ The two figures show that the sample countries in general experience a drop in $F D$ prior to democratization, which is in accordance with the view that worsened economic conditions are associated with a subsequent democratization. After democratization, FD appears to move slightly upwards on average in one to five years, followed by a surge in five to ten years.

Figure 4.2 describes the standard deviation of the $F D$ growth rate before and after a stable democratization for whole the sample and subsamples. Democratization has led to a substantial rise in the standard 


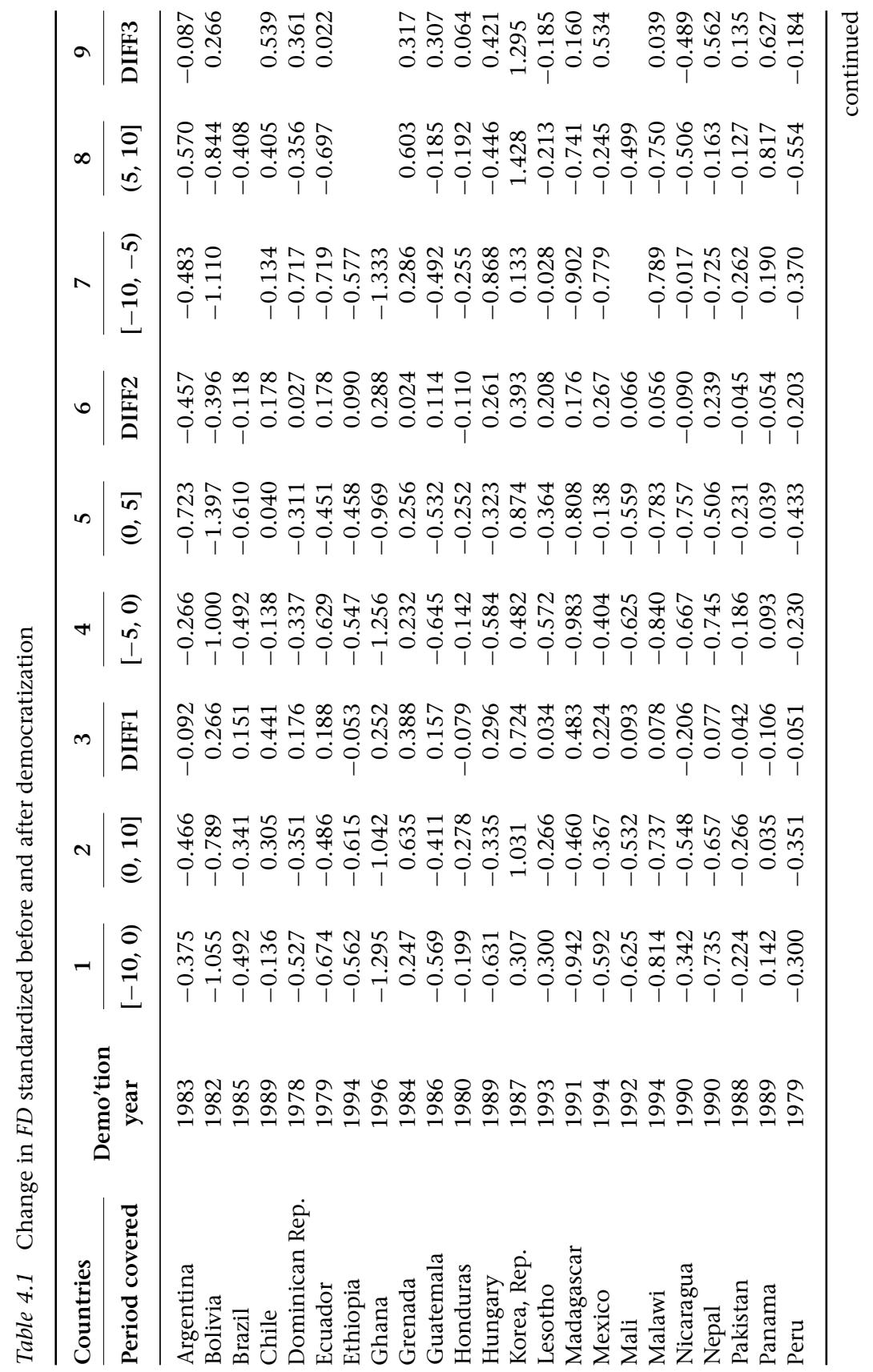




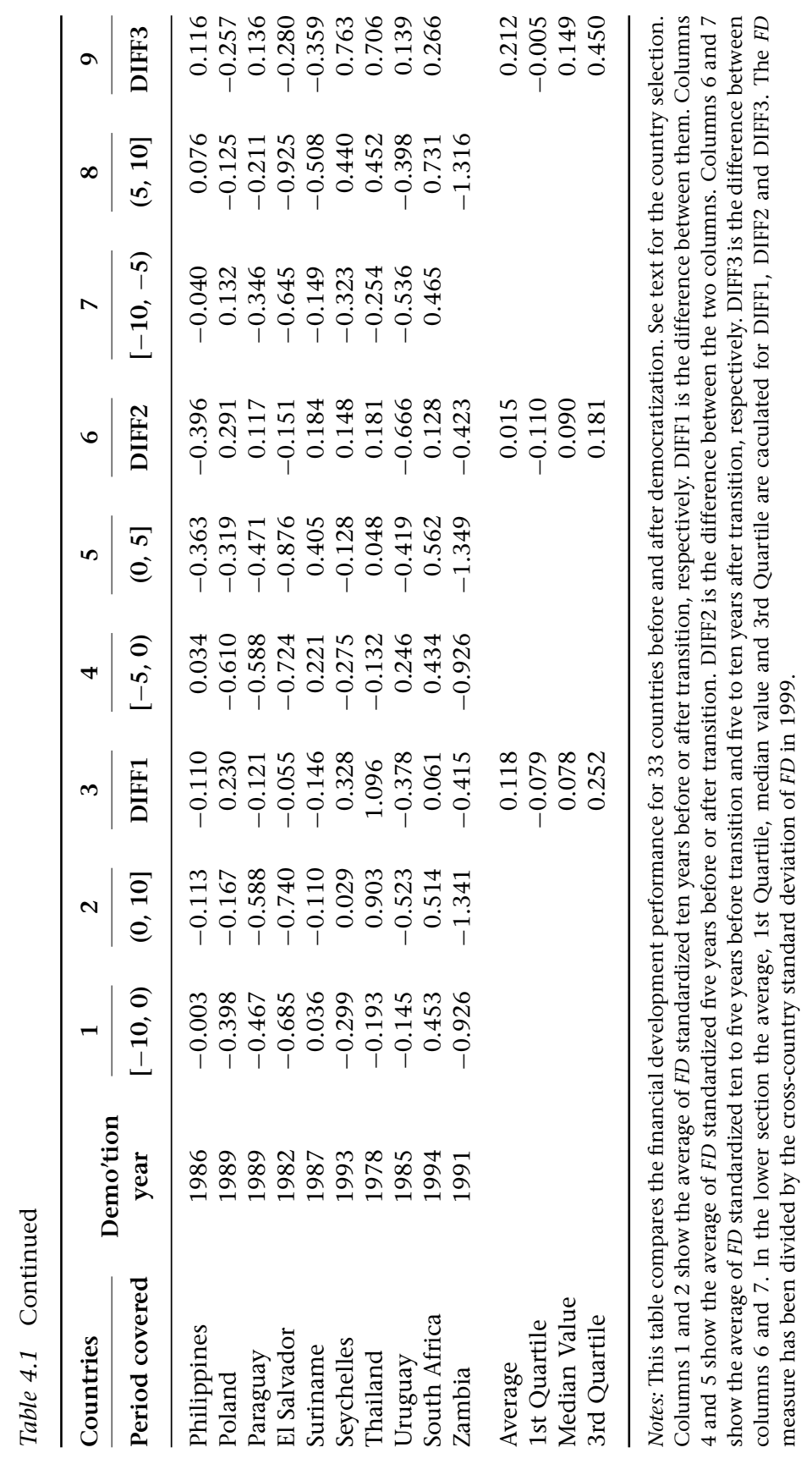



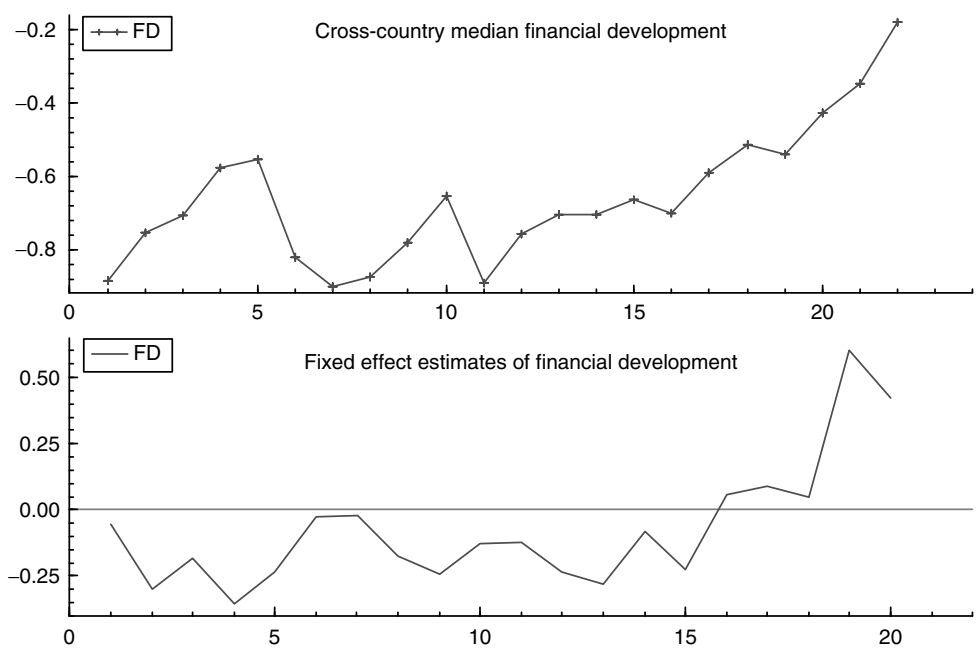

Figure 4.1 Financial development ten years before and after democratization

Note: 33 democratization countries, 1960-99. Upper figure shows the crosscountry median financial development for these countries. Lower figure plots the coefficients of fixed-effect estimate of 20 time dummies before and after democratization. The regression is estimated by OLS, in which the country effects, time effects, controlling variables like $L G D P, O P E N C, B M P$ and $C I$ are included.

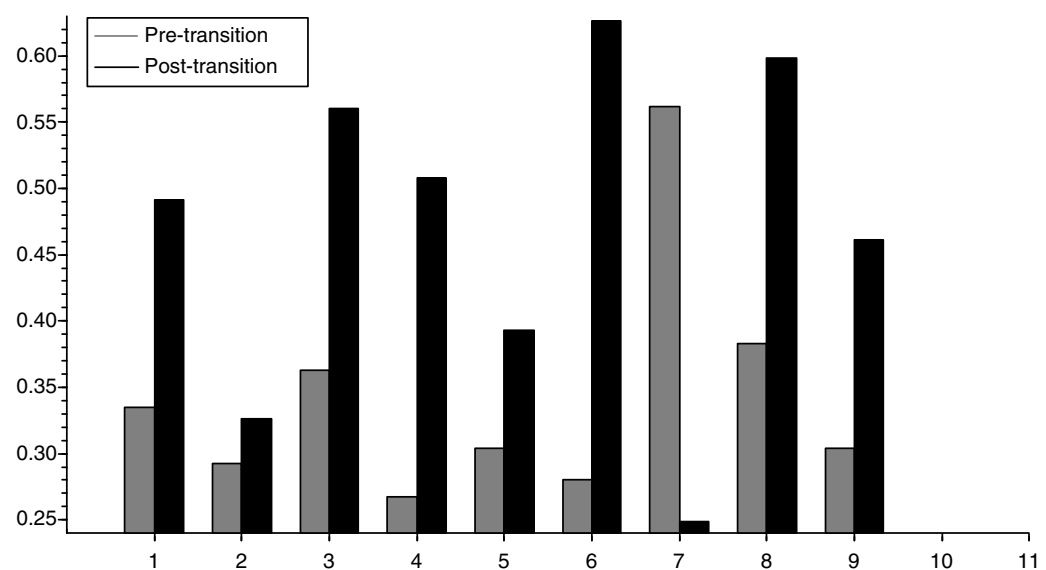

Figure 4.2 Volatility of financial development ten years pre/postdemocratization

Note: 33 democratization countries, 1960-99. This figure shows the volatility of financial development, standard deviation of $F D$ growth rate, for the whole sample and eight subsamples before and after democratization. 
deviation of the $F D$ growth rate for the whole sample. Regional groups like Latin American ( $L A C$ ) and Sub-Saharan African (SSA) countries experience a higher standard deviation of the $F D$ growth rate, but Asian countries (ASIA) do not. ${ }^{81}$ The standard deviations of the FD growth rate in income groups, like low-income countries (INCLOW) and middleincome countries (INCMID), and in legal origin groups, like British legal origin countries $\left(L E G_{-} U K\right)$ and French legal origin countries ( $\left.L E G_{-} F R\right)$, increases after their democratic transition. An increase in the standard deviation of the $F D$ growth rate may reflect the fact that the removal of institutional obstacles after democratic transition could bring about short-run investment booms, reflected in a more volatile FD growth rate.

\subsubsection{Regression results}

Section 4.5.1 does provide some interesting results on the impact of democratic transition on financial development. However, this evidence is preliminary, and not convincing. In what follows we present the econometric evidence, for both the whole sample and three subsamples. 82

\subsubsection{Whole sample results}

Table 4.2 reports the results for the whole sample, including estimation by OLS, LSDV, LSDVC and SYS-GMM. For each estimate, the first column is the baseline specification in which the income level and trade openness are present, while the second column controls for the black market premium and aggregate investment. The point estimate and the approximate standard error of the long-run effect for each model are reported. Given the estimated models, the OLS, LSDV, LSDVC and SYSGMM estimates require that the long-run effect must have same sign as the short-run effect. For the SYS-GMM estimate, the table reports serial correlation tests, a Sargan test and a Difference Sargan test. The serial correlation tests are used to examine the null hypothesis of no first-order serial correlation and no second-order serial correlation respectively in residuals in first differences. Given the errors in levels are serially uncorrelated, we would expect to find significant first-order serial correlation, but no significant second-order correlation in the first-differenced residuals. The Sargan test of over-identifying restrictions is used to examine the overall validity of the instruments by comparing the sample moment conditions with their population analogue. The Difference Sargan test, proposed by Blundell and Bond (1998), is used to test the null hypothesis that the lagged differences of the explanatory variables are uncorrelated with the errors in the levels equations. 


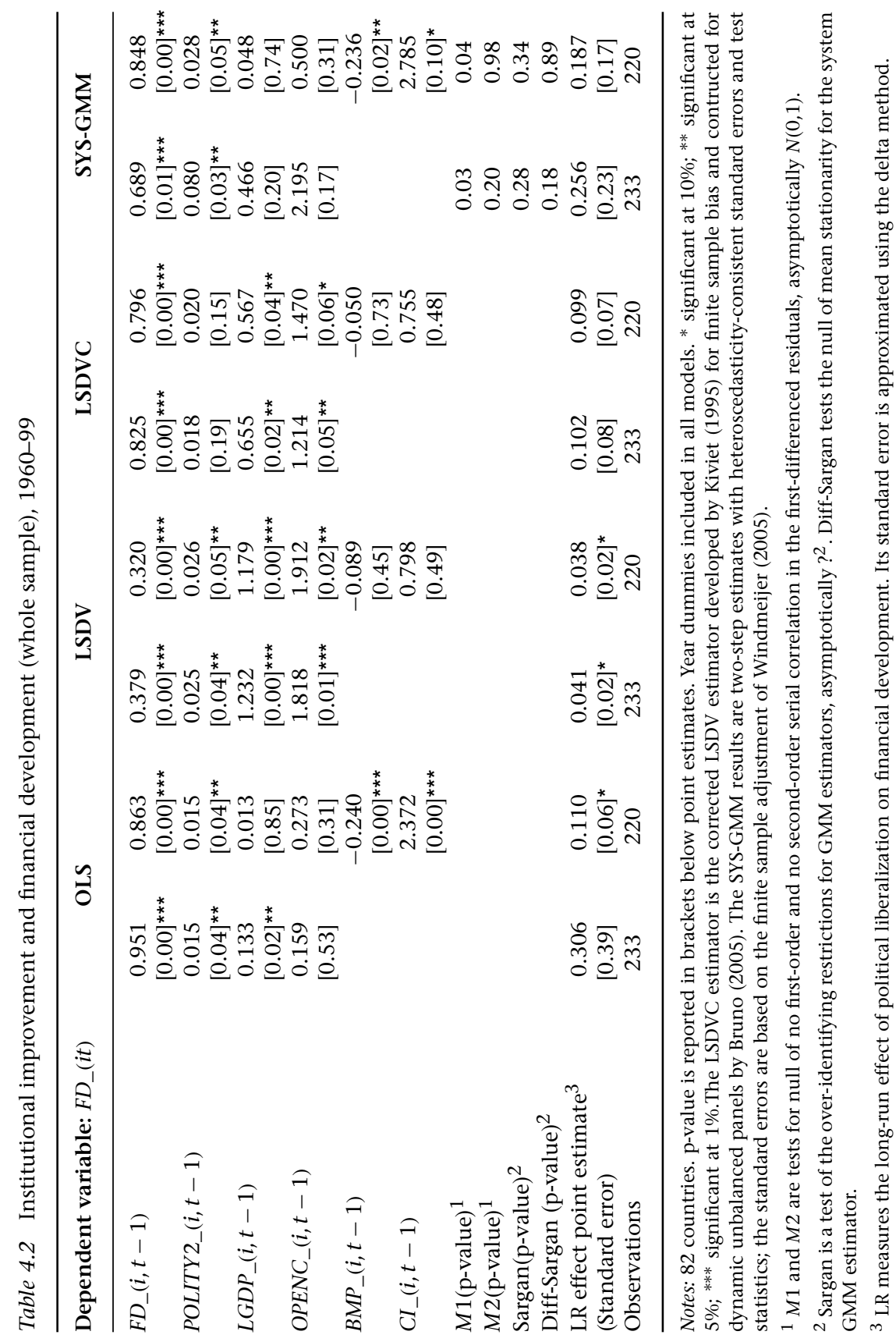


It is worth noting that, first, the autoregressive parameter estimated by LSDVC and SYS-GMM lies in the interval defined by the OLS levels and LSDV estimates. Recall that, in AR(1) models, the OLS levels estimate of the autoregessive parameter is biased upwards in the presence of fixed effects and the LSDV estimate is biased downwards in a short panel. A consistent estimate of the autoregressive parameter can be expected to lie in between the OLS levels and LSDV estimates. It is a simple indication of the presence of serious finite sample biases when particular estimates fail to fall into this interval or are very close to the bounds.

Both OLS and LSDV estimates indicate a significant positive effect of democratization on financial development although they are biased in opposite directions. The LSDVC estimator suggests evidence at the $20 \%$ significance level. The SYS-GMM estimate provides strong evidence that the improvement in institutional quality is associated with financial development, and the diagnostic tests, including the first- and secondorder serial correlation tests, Sargan test and Difference Sargan test, support this. In general, the coefficients on the GDP level, trade openness and aggregate investment are positively signed, while the coefficient of the black market premium is negatively signed. The long-run effects in the cases of the OLS and LSDV estimates have been found to be positive and stable. However, the long-run effects for LSDVC and SYS-GMM are less precisely estimated.

In general, the table provides evidence, which is not due to unobserved heterogeneity or endogeneity biases, that democratization is followed by advances in financial development at least in the short run.

\subsubsection{Subsamples}

In principle, the system GMM and LSDVC estimates impose homogeneity on all slope coefficients. One concern over the above findings is that these parameters may be heterogeneous across countries. A natural way to confront this problem is to investigate subsamples, which are more homogeneous. We turn to three subsamples in this section: lowerincome countries, ethnically diverse countries and French legal origin countries. ${ }^{83}$ Since the cross section dimensions of these samples are relatively small, LSDVC is expected to be more appropriate than SYS-GMM for them.

Table 4.3 presents the results for the lower-income countries, made up of low-income and lower-middle-income countries, covering the majority of the developing countries. We find strong evidence of a positive effect of institutional improvement on financial development in the short run for every estimator. The LSDVC should be the most reliable 


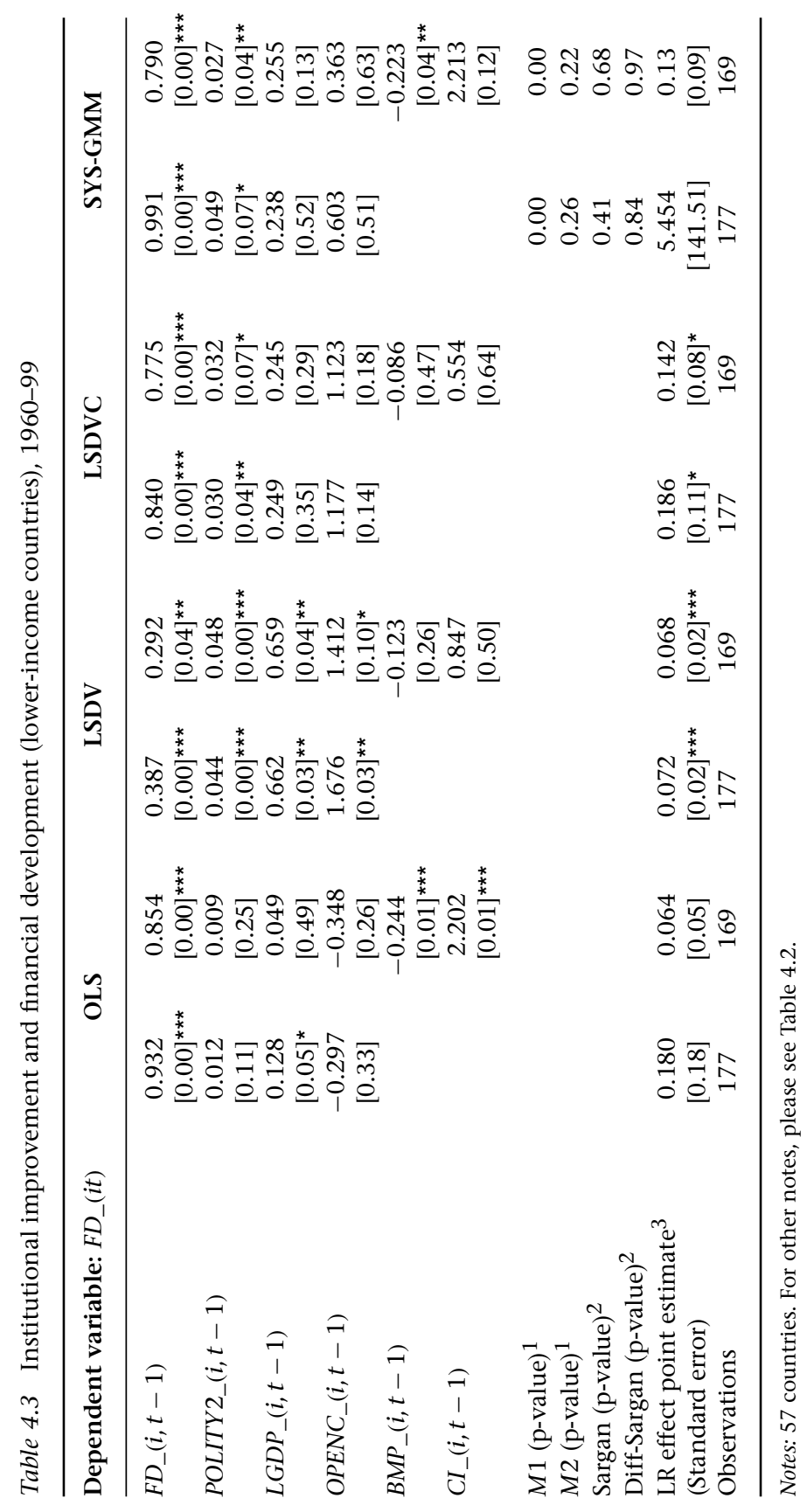


estimator, given the above discussion. Moreover, it also indicates that the effect of improved institutional quality on financial development is sustained into the long run. Trade openness enters the models at the $20 \%$ significance level.

Table 4.4 shows the results for ethnically diverse countries which have a level of ethnic fractionalization greater than the sample median. We find strong evidence of the positive effect of institutional improvement on financial development in the short run. The autoregressive parameter estimates from LSDVC and SYS-GMM are very close. The LSDVC estimates suggest a positive effect of political liberalization on financial development at the 20\% significance level with GDP and trade openness entering significantly. The SYS-GMM estimates provide much stronger evidence, in which GDP and trade openness are present at the $20 \%$ significance level. The long-run effects and approximate standard errors are in general less precisely estimated except for the case of the OLS and LSDV estimates.

The results for countries with French legal origin are reported in Table 4.5. This selection is essentially inspired by the work of La Porta et al. (1998), which regards legal origin as a main determinant of financial development. The experiments for British, German (LEG-GE) and Scandinavian (LEG-SC) legal origin groups produce no evidence in favour of a causal link from institutional improvement to financial development.

First it is worth noting that the autoregressive parameter estimated by SYS-GMM in the baseline model lies outside of the interval defined by the OLS and LSDV estimates, further implying the LSDVC may be a more reasonable estimator in this context. The LSDVC estimates typically show evidence in support of a positive effect of institutional improvement on financial development for French legal origin countries at the 15\% significance level. The finding seems to be in line with La Porta et al. (1998), which claims that the main characteristic for countries with French legal origins is that private property rights are generally neglected, while British legal origin countries care more about private property owners. The finding supports a tentative hypothesis that democratization in French legal origin countries tends to change the status of private property owners in the national economy, and is thus conducive to financial development.

In sum, the above studies on subsamples have produced a coherent set of findings: improved institutional quality leads to greater financial development, at least in the short run. In the group of lower-income countries, a significant long-run effect is also observed. In general, we 


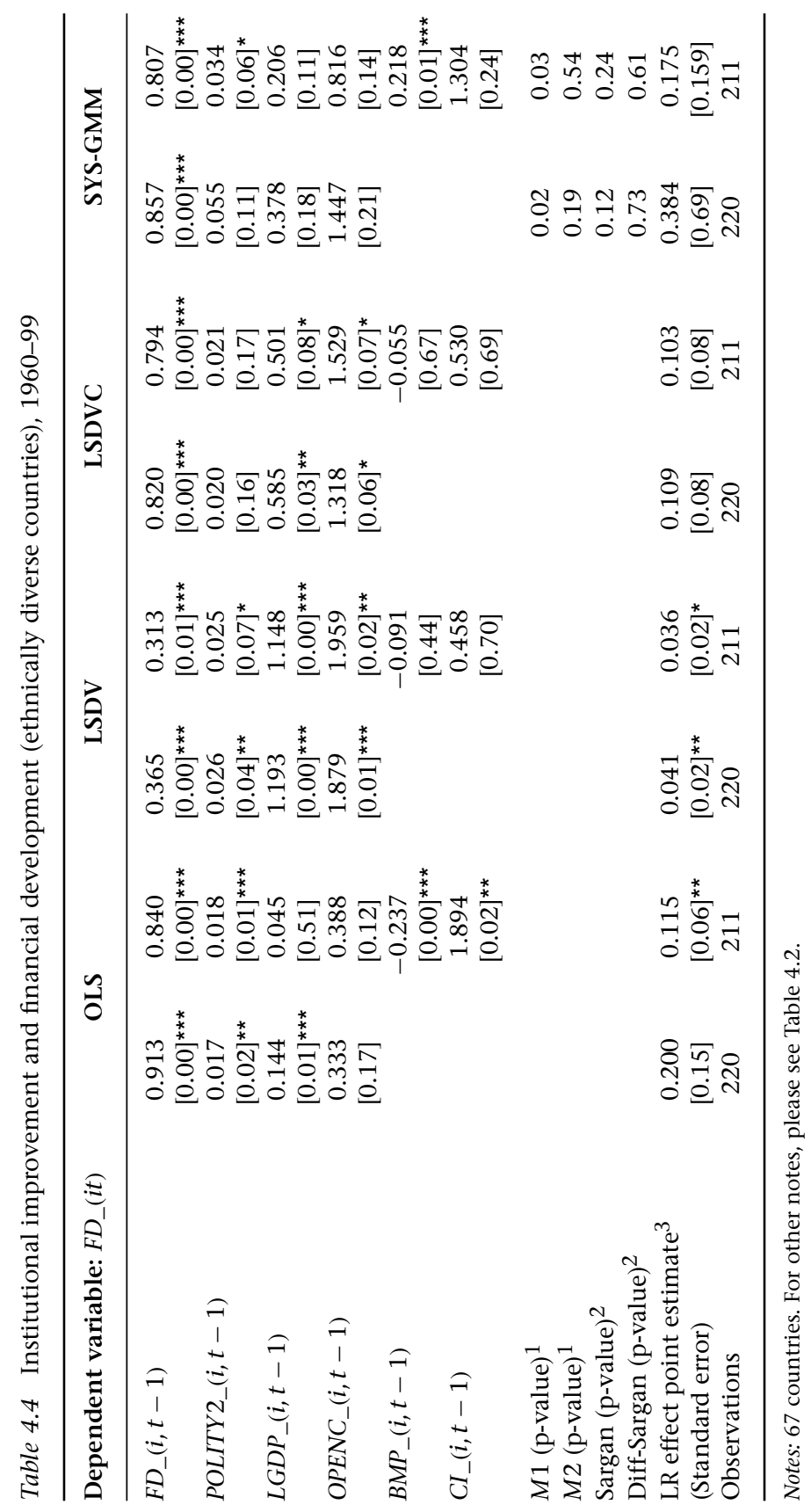




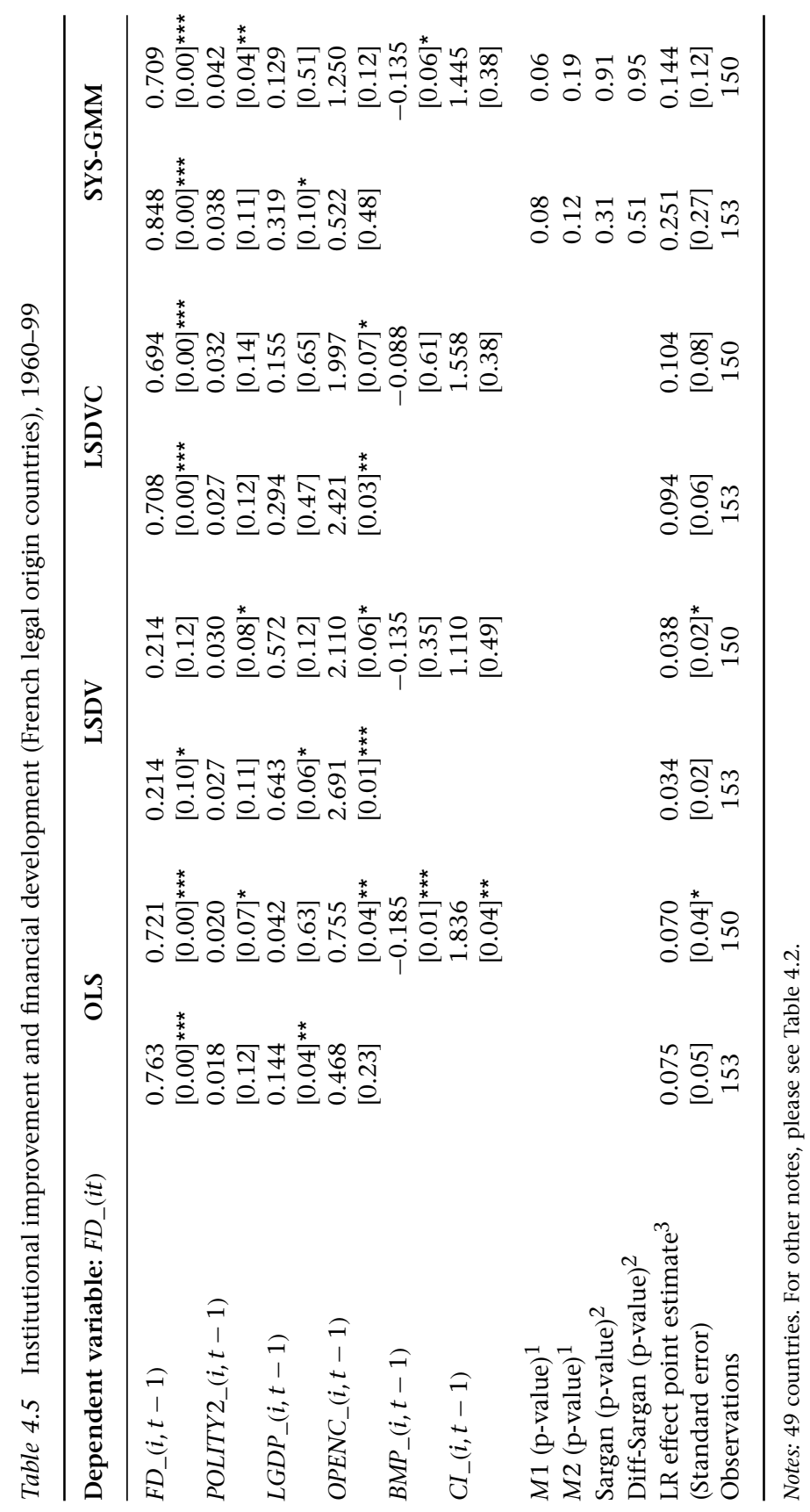


find the black market premium has a negative effect, while GDP, trade openness and aggregate investment enter positively.

\subsection{Conclusion}

This research examines whether institutional improvement stimulates financial development using a panel of 90 economies over the period 1960-99. By comparing newly developed panel data techniques, including bias-corrected LSDV and system GMM estimators, this research shows that improved institutional quality is associated with increases in financial development at least in the short run, and this is particularly true for lower-income, ethnically divided and French legal origin countries. For the lower-income countries, this effect is expected to persist over longer horizons. The preliminary evidence from a "before-and-after" approach indicates that, in general, democratic transitions are typically preceded by low financial development, but followed by a short-run boost in, and greater volatility of, this.

The findings of this research highlight the influence of institutional innovation on the supply side of financial development. They shed light on the strong and robust relationship between institutional quality and economic performance, and present further grounds for institutional reform.

The findings in the panel data study on the coexistence of the effect of institutional innovation, GDP and trade openness on financial development are very significant. First, the study enriches the evidence for an openness-finance nexus. Huang and Temple (2005)'s cross section and panel data study suggests that trade openness is very likely to boost financial development, for which institutional improvement could serve as one channel. The IMF (2003) indicates the possible existence of such a channel by concluding that "greater openness to trade and stronger competition are conducive to institutional improvement, and thus to growth". However, the findings of this research tend to suggest that there are additional channels via which more open policies exert a positive effect on financial development. The findings are also consistent with Rajan and Zingales (2003)'s claim that trade openness is helpful for changing incumbents' willingness to promote financial development.

Second, the study has implications for economic and political reform. Giavazzi and Tabellini (2004) argue that "studying the effects of each reform (economic and political reform) individually can be misleading" and there are positive feedback effects and interaction effects between 
economic and political liberalization. The findings of this chapter seem to be consistent with their findings on the interaction effects, in the sense that institutional reform under an open economic environment exerts an additional boost to investment and economic growth, and thus to financial development. 


\section{Appendix tables}

Table A4.1 The variables

\begin{tabular}{|c|c|c|}
\hline Variable & Description & Source \\
\hline$F D$ & $\begin{array}{l}\text { Index for financial development in this paper, } \\
\text { mainly measuring the size of financial } \\
\text { intermediary development. It is the first } \\
\text { principal component of } L L Y, P R I V O \text { and } B T O T \text {. }\end{array}$ & \\
\hline$L L Y$ & $\begin{array}{l}\text { Liquid Liabilities, the ratio of liquid liabilities } \\
\text { of financial system (currency plus demand and } \\
\text { interest-bearing liabilities of banks and } \\
\text { nonbanks) to GDP. }\end{array}$ & $\begin{array}{l}\text { Financial Development } \\
\text { and Structure Database } \\
\text { (FDS) in World Bank, } \\
2008\end{array}$ \\
\hline PRIVO & $\begin{array}{l}\text { Private Credit, the ratio of credits issued to } \\
\text { private sector by banks and other financial } \\
\text { intermediaries to GDP. }\end{array}$ & FDS, 2008 \\
\hline BTOT & $\begin{array}{l}\text { Commercial-Central Bank, the ratio of } \\
\text { commercial bank assets to the sum of } \\
\text { commercial bank and central bank assets. }\end{array}$ & FDS, 2008 \\
\hline POLITY2 & $\begin{array}{l}\text { The index for the degree of democracy. It is the } \\
\text { "polity2" in PolityIV Database. }\end{array}$ & $\begin{array}{l}\text { PolityIV Database } \\
\text { Marshall and Jaggers } \\
\text { (2008) }\end{array}$ \\
\hline$L G D P$ & Real GDP per capita (Chain) in log. & Penn World Table 6.2 \\
\hline OPENC & $\begin{array}{l}\text { The sum of exports and imports over GDP (at } \\
\text { current prices). The regression uses } \\
\log (1+\text { OPENC/100). }\end{array}$ & Penn World Table 6.2 \\
\hline$C I$ & $\begin{array}{l}\text { The sum of investment over real GDP per } \\
\text { capita (using domestic prices). The regression } \\
\text { uses CI/100. }\end{array}$ & Penn World Table 6.2 \\
\hline$B M P$ & $\begin{array}{l}\text { Black market premium (\%, means zero). The } \\
\text { regression uses } \log (1+\mathrm{BMP} / 100) \text {. }\end{array}$ & $\begin{array}{l}\text { Global Development } \\
\text { Network (GDN), } 2002\end{array}$ \\
\hline INCLOW & Dummy for low-income group & GDN, 2002 \\
\hline INCMID & $\begin{array}{l}\text { Dummy for middle-income group, made up of } \\
\text { lower-middle-income and low-income } \\
\text { countries }\end{array}$ & GDN, 2002 \\
\hline ETHFRAC & Dummy for ethnic fractionalization & GDN, 2002 \\
\hline$L E G_{-} U K$ & Dummy for British legal origin & GDN, 2002 \\
\hline$L E G_{-} F R$ & Dummy for French legal origin & GDN, 2002 \\
\hline$L E G_{-} G E$ & Dummy for German legal origin & GDN, 2002 \\
\hline$L E G \_S C$ & Dummy for Scandivanian legal origin & GDN, 2002 \\
\hline$A S I A$ & Dummy for Asian countries & GDN, 2002 \\
\hline$L A C$ & Dummy for Latin American countries & GDN, 2002 \\
\hline$S S A$ & Dummy for Sub-Sarahan African countries & GDN, 2002 \\
\hline
\end{tabular}


124 Determinants of Financial Development

Table A4.2 Descriptive statistics

\begin{tabular}{llccrrl}
\hline Variable & & Mean & Std. Dev. & Min & Max & Observations \\
\hline FD & overall & -0.61 & 1.17 & -2.91 & 1.85 & $\mathrm{~N}=341$ \\
& between & & 1.09 & -2.77 & 2.53 & $\mathrm{n}=90$ \\
& within & & 0.56 & -2.45 & 4.48 & $\mathrm{~T}-\mathrm{bar}=3.79$ \\
POLITY2 & overall & -1.83 & 6.39 & -10.00 & 10.00 & $\mathrm{~N}=438$ \\
& between & & 5.37 & -9.78 & 9.83 & $\mathrm{n}=90$ \\
& within & & 3.56 & -12.70 & 10.92 & $\mathrm{~T}-\mathrm{bar}=4.87$ \\
LGDP & overall & \multirow{2}{*}{7.73} & 0.84 & 5.89 & 10.06 & $\mathrm{~N}=399$ \\
& between & & 0.86 & 6.28 & 10.06 & $\mathrm{n}=86$ \\
& within & & 0.26 & 6.70 & 8.73 & $\mathrm{~T}-\mathrm{bar}=4.64$ \\
OPENC & overall & 0.43 & 0.19 & 0.07 & 1.18 & $\mathrm{~N}=399$ \\
& between & & 0.19 & 0.13 & 1.08 & $\mathrm{n}=86$ \\
& within & & 0.08 & 0.16 & 0.78 & $\mathrm{~T}-\mathrm{bar}=4.64$ \\
CI & overall & 0.13 & 0.08 & 0.01 & 0.39 & $\mathrm{~N}=399$ \\
& between & & 0.07 & 0.02 & 0.31 & $\mathrm{n}=86$ \\
& within & & 0.04 & 0.00 & 0.35 & $\mathrm{~T}-\mathrm{bar}=4.64$ \\
BMP & overall & 0.33 & 0.66 & -0.04 & 7.64 & $\mathrm{~N}=402$ \\
& between & & 0.47 & 0.00 & 3.17 & $\mathrm{n}=88$ \\
& within & & 0.53 & -1.65 & 5.88 & $\mathrm{~T}-\mathrm{bar}=4.57$ \\
\hline
\end{tabular}

Note: Appendix Table A4.1 describes all variables in detail. 